\title{
Motion Synthesis and Coordinated Control in the Multi-Axle-Driving-Vehicle
}

\author{
Yunhua Li and Liman Yang \\ Beijing University of Aeronautics and Astronautics
}

China

\section{Introduction}

Multi-axle-Driving-vehicle is a kind of the mobile robot and it also belongs to the construction machinery which generally has heavy load-capacity and huge size. As shown in Fig.1 and Fig.2, both hoisting-girder transporter and DCY900 transportation vehicle are multi-axle-driving vehicles. In order to decrease the ground-contacting pressure, the ground-clearance of the vehicle chassis and the size of the tyre, and to increase the loadingcapacity and the passing performance of the vehicle, the multi-axle driving and independently controlled steer axles are employed, and also distributed electro-hydraulic proportional control is applied to the heavy type of vehicles. Such a large-scale vehicle has to deal with the complex motion control problem. The controlled output motions of multiple axles should meet certain matching condition or corresponding relationship so as to make the whole vehicle to realize the expected contouring motion trace. For example, all the powered steer axles have to be coordinately controlled in real time in order to achieve smooth and accurate steering motion without slipping and sliding. Besides the steering function, the steer axles are also designed to automatically level the vehicle body when it moves in an uneven terrain. It follows that the motion synthesis and coordinated control methods should concurrently cope with the tasks and motions of multiple subsystems.

Conventionally, coordinated control of a simple mechatronics system is realized through a centralized control scheme in which each of the actuators is directly linked to the controller through cable in a point-to-point manner. However, for a complex multi-tasking mechatronic system with a large number of subsystems and actuators, such a control scheme is impractical. This is especially true for a large-scale multi-axle vehicle because it is huge in size and has many distributed subsystems to be arranged anywhere in the vehicle. If a centralized control scheme is employed, it will result in a very messy wiring scheme.

Thanks for the advanced network technologies, which provide us an effective way to realize coordinated control for the multi-axle driving vehicles. In a network environment, all the control devices such as sensors, actuators, and controllers are distributed and simply linked together through network interfaces (e.g., Field-bus, Industrial Ethernet, and mobile net) so as to achieve coordination and resources sharing efficiently. In convention, a network-based mechatronic control system is called an NCS (Networked Control System), which has many advantages over a centralized control system, e.g., low installation cost, ease of system maintenance, simplicity in failure diagnosis, and high flexibility in system management 
(Lian et al., 2002). Therefore, the NCS is an ideal solution for the motion synthesis and coordinated motion control of large-scale and complex mechatronic systems.

The conventional approach for motion synthesis and coordinated motion control employs the actuator-level tracking error as the major performance index. A feedback and feedforward controller is then individually designed for each axis to achieve its planned motion profile. Such a control strategy is not appropriate for a complex mechatronics system to accomplish multitasks with distributed and coordinated operations. Apparently, it will be more effective to evaluate the contour-tracking accuracy, i.e., the difference between the actual and targeted motion trajectories in the system level. Besides, an effective feedback and feedforward controller combined with a cross-coupled control law can be developed to significantly improve the contour control accuracy. There are a number of representative works in the related areas. A multi-axis task-coordination approach (Tomizuka \& Niu, 2001) is presented to form the first loop of the feedback and feedforward control, in which an accurate plant model is needed. A new variable gain cross-coupled control method based on system-level tracking errors is proposed (Yeh \& Hsu, 2003). A kind of task-space nonlinear sliding mode observer is introduced to control a synchronized double-cylinder system. Through theoretical analysis and Lab-based experimental study, the effectiveness of the system-level contour control strategy has been demonstrated (Sun\& George, 2002). A multiaxis motion synchronization strategy is developed in which the asymptotic convergence of both tracking and synchronization errors are achieved (Liu, 2005). In order to improve contouring performance of the retrofitted milling machine, a self-tuning adaptive control strategy combined with cross-coupled control of axial motion is designed (Yan \& Lee, 2005). For large-scale multi-axle vehicles, NCS-oriented motion synthesis framework and crossedcouple control algorithm are investigated ( $\mathrm{Li}$ et al., 2007) and the practical engineering applications on Hoisting-girder transporter are explored (Yang et al., 2009).

In this chapter, addressing to the motion synthesis and coordinated control of multi-axle driving vehicles, we shall discuss the basic background knowledge, the operation principle, the kinematical models and coordinated control methodology to be concerned in the traveling and steering systems of the multi-axle driving vehicles. Firstly, the NCS fundamental knowledge and common motion synthesis modes of vehicle steering are outlined, and a kind of networked-based travelling and steering system is proposed for multi-axle construction machinery. Then, the kinematical models of two-axle vehicle and multi-axle vehicle are respectively established. Furthermore, for multi-axle driving vehicle, the travelling and steering hydraulic system design are provided, and the multi-axle coordinated control strategy are developed. Finally, the experimental investigations on the DCY transportation vehicle and track-laying machine for high speed railway are explored.

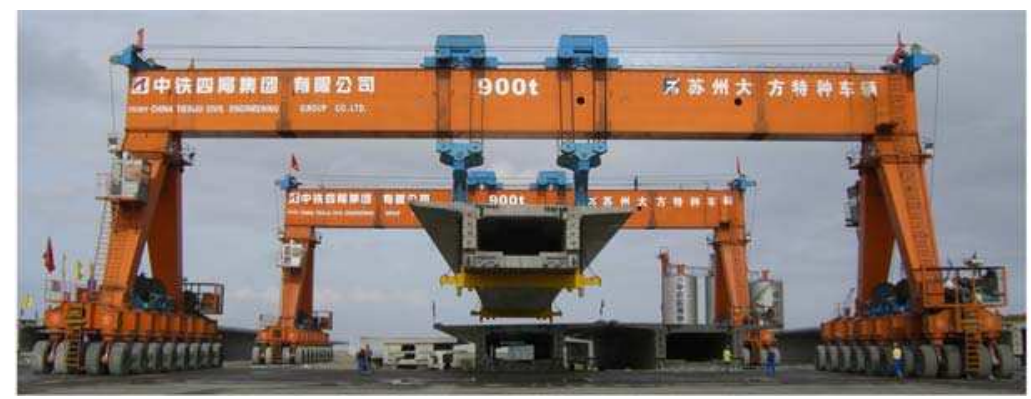

Fig. 1. Hoisting-girder transporter with 900T load 


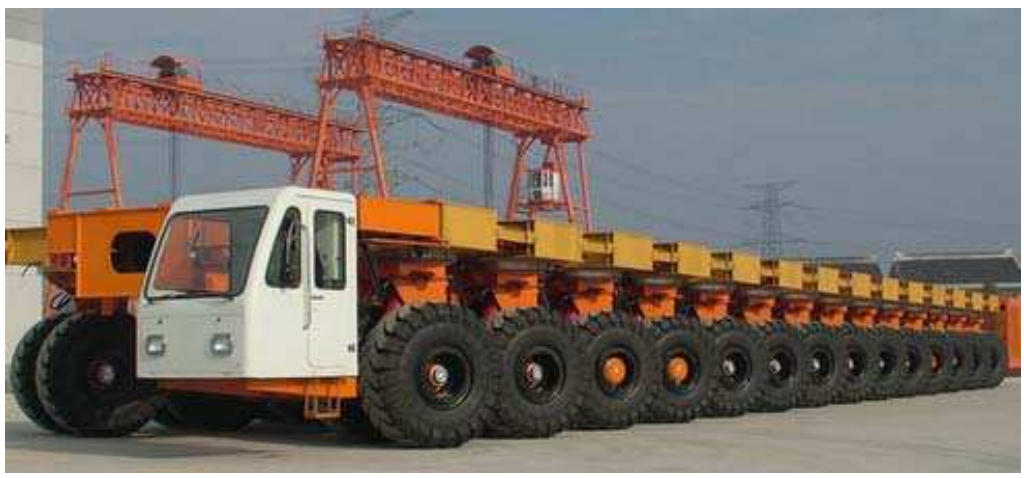

Fig. 2. DCY900 powered transportation vehicle

\section{Fundamental knowledge}

\subsection{Networked control system}

A typical network control system (NCS) is shown in Fig.3. It is a spatially distributed system in which the communication between sensors, actuators, and controllers occurs through a shared band-limited digital communication network (Hespanha et al., 2007). However, in broad sense, NCSs also include many types even covering traditional DCS and remote networked control systems based on internet.

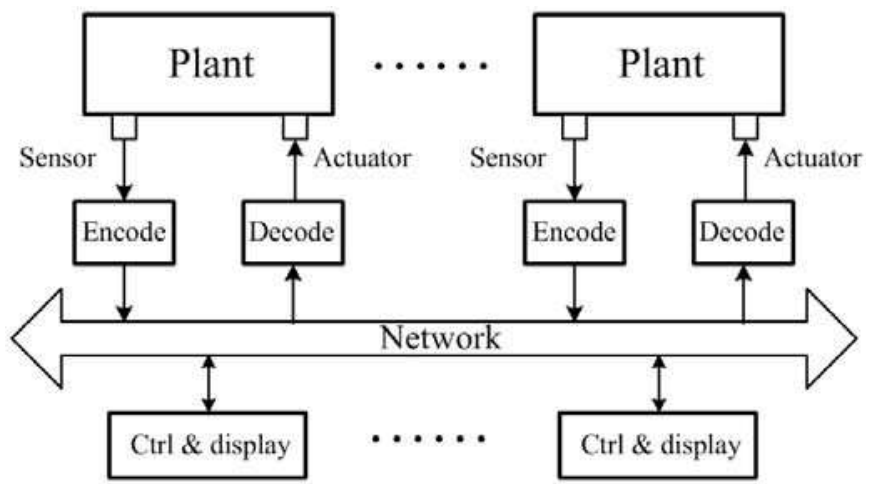

Fig. 3. General NCS architecture

In view of physical realization, the NCS can be classified into different types such as serialbus configuration, Field-bus configuration, mobile network, and industry Ethernet etc. According to the control node types, the NCS can also be classified into three basic styles: the sensor/actuator node style, the coupling node style, and the controller node style. In the former two styles, the control closed-loops are built by network communication, in which the sensing and controlling data are transmitted by network. While last style is similar to DCS (Distributed Control System) which almost real control tasks are executed in intelligent nodes and only some commands and warning signals are transmitted on network. The mathematical descriptions of the three kinds of NCS are given as follows. 
a. Sensor/actuator node style NCS

Considering the $i$ th actuator node, the dynamic equation and control law are respectively as follows:

$$
\left\{\begin{array}{l}
\dot{\boldsymbol{x}}_{i}=\boldsymbol{f}_{i}\left(\boldsymbol{x}_{i}, u_{i}\right), y_{i}=h_{i}\left(\boldsymbol{x}_{i}\right) \\
u_{i}=u_{i}\left(r_{i}, y_{i}\right)
\end{array}\right.
$$

where $\boldsymbol{x}_{i}, \boldsymbol{f}_{i} \in \mathbb{R}^{n_{i}}, \boldsymbol{x}_{i}$ is the state vector $(i=1,2, \ldots, m), m$ denotes the node number, and $n_{i}$ denotes the dimension number of the state vector of the plant to be controlled by the $i$ th node. The above equation set consists of the state equations for the actuators and the controlled plants, and the output equations (at the actuator nodes) as well as the control algorithm for master control node. The outputs and control signals of the each node are transmitted through network. Obviously, it can be also view as a kind of generalized centralized-control system connected through Field-bus.

b. Coupling node style NCS

For this case, there are $n_{i}$ plants to be controlled by the $i$ th node. The dynamic equation and the control law are respectively as follows:

$$
\left\{\begin{array}{l}
\dot{\boldsymbol{x}}_{i l}=\boldsymbol{f}_{i l}\left(\boldsymbol{x}_{i l}, u_{i l}\right), y_{i l}=h_{i l}\left(\boldsymbol{x}_{i l}\right) \\
u_{i l}=u_{i l}\left(r_{i l}, y_{i l}\right)
\end{array}\right.
$$

where $\boldsymbol{x}_{i l}, \boldsymbol{f}_{i l} \in \mathbb{R}^{n_{i l}}\left(i=1, \cdots, m ; l=1, \cdots, n_{i}\right), \boldsymbol{x}_{i}$ is the state vector, $m$ denotes coupling node number, $n_{i}$ denotes the number of the plants controlled by the $i$ th node, and $n_{i l}$ denotes the dimension number of state vector of the $l$ th plant controlled by the $i$ th coupling node. Equation (2) is composed of the state equations and the output equations of plants controlled by the coupling node as well as the control algorithm of the master control node. The outputs and control signals of the nodes are transmitted through network. Style 2 is degenerated into style 1 when $l=1$.

c. Controller node style NCS

$$
\left\{\begin{array}{l}
\dot{\boldsymbol{x}}_{i l}=\boldsymbol{f}_{i l}\left(\boldsymbol{x}_{i l}, u_{i l}\right), y_{i l}=h_{i l}\left(\boldsymbol{x}_{i l}\right) \\
u_{i l}=u_{i l}\left(r_{i l}, y_{i l}\right), r_{i l}=r_{i l}\left(t_{k}\right)
\end{array}\right.
$$

where $\boldsymbol{x}_{i l}, \boldsymbol{f}_{i l} \in \mathbb{R}^{n_{i l}}\left(i=1, \cdots, m ; \quad l=1, \cdots, n_{i}\right), \boldsymbol{x}_{i}$ is the state vector, $m$ represents the controller node number, $n_{i}$ represents the output number of the plants controlled by the $i$ th controller node, and $n_{i l}$ is the dimension number of the state vector of the $l$ th plant controlled by the $i$ th node. Equation (3) is composed of the state equations and the output equations of the plants controlled by the controller nodes, the control law determined by the $i$ th node, and the reference control signals produced by motion planning. The outputs and control signals of the nodes are transmitted through network.

In general, an NCS may contain the three basic styles mentioned above or their hybrid styles. For the third style of NCS, its logic and function diagram is shown in Fig.4, which describes the system logic and function arrangement, the relationship of transmitted signals, and the control loops. 


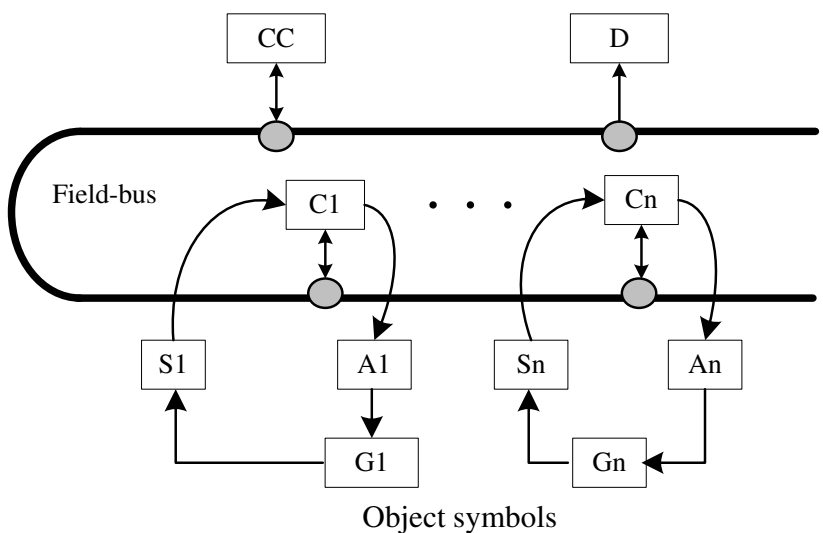

CC: scheduler and supervisor node, S: sensor, A: actuator

$\mathrm{C}$ : controller node, D: display node

Fig. 4. Block diagram of an NCS

In the third style of NCS, a mechatronic system that consists of multiple distributed subsystems is equivalent to a MIMO system with transmitting delay. The output-motion synthesis depends on a set of tasks performed on the nodes. Each node can control one or several plants with a feedback or feedforward controller. Information exchange among the nodes through field-bus makes all plant outputs be controlled for system-level contour tracking so that motion synthesis and coordinate motion control can be realized.

\subsection{Motion synthesis modes of steering system}

The conventional motion synthesis modes include mechanical (typically like linkage, gear, and cable), pneumatic, hydraulic and electrical transmissions. However, they are unsuitable for large-scale multi-axle vehicles in which many spatially distributed physical components are needed and the complicated operation functions are required usually. For instance, the mechanical mode is very difficult to realize accurate motion synthesis and multiple manipulation modes. The electrical scheme has to face the problems like as complex wiring, difficult maintenance, high fault ratio and hard expansion. From the preceding introduction of NCS, we can see that the distributed and networked structure of NCS is helpful for information share and integration as well as intelligent decision-making. As result, it provides an ideal framework for the motion synthesis and coordinated motion control of large-scale and distributed construction machinery (Li \& Yang, 2005).In this section, the conventional ways of mechanical and full hydraulic motion synthesis are described with example of the construction vehicle's steering control and a new based-networked synthesis scheme is developed.

a. Mechanical steering

The earliest steering scheme is Ackerman's steering trapezium, it is shown in Fig.5. The motion synthesis is undertaken by the linkage mechanism and the wheel system. It has the advantages of exact transmission, reliability, easy fabrication, simple operation and high transmission efficiency. But, it can't usually realize the stepless speed regulation and the transmitting of the power for long distance, and also its structure is also complicated relatively. The collocation of the transmission mechanism is very difficult and the motions 
among mechanisms are not easy to control and integrate, so that it doesn't realize the flexible multi-mode steering. It also makes against decreasing the gap to ground and improving the passing and smoothing ability. Due to the above disadvantages, this mechanical transmitting mode only works in the special condition, thus it can't fit the agile manipulating demands of modern construction machinery.

The electrical, pneumatic, or hydraulic steering scheme can solve the problem of the forceassistant, which makes it possible to the steer the heavy vehicle. Among of them, because of high power-density and rapid response, the hydraulic power steering is widely used in the construction machinery.

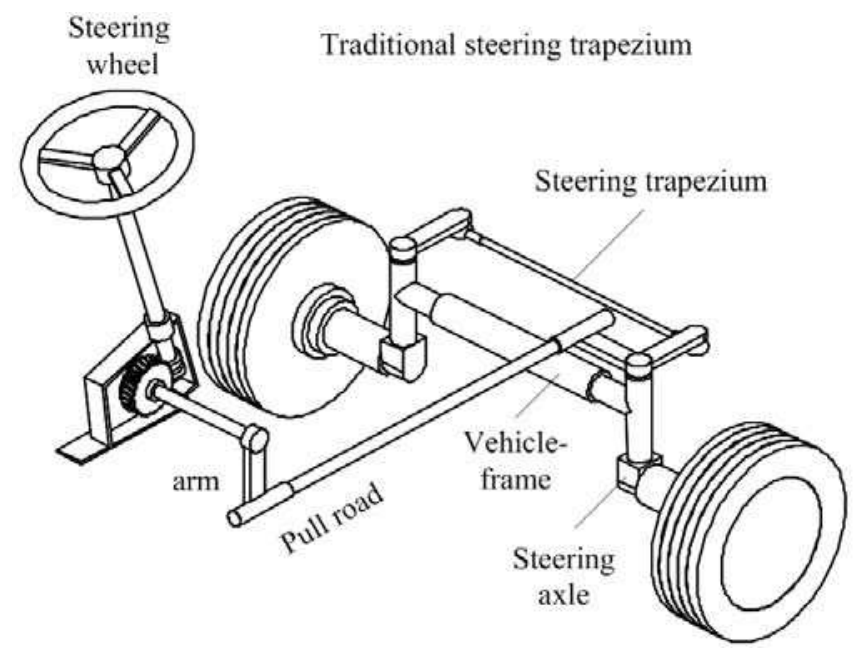

Fig. 5. Ackerman's steering trapezium

b. Full-hydraulic steering

The most common type of hydraulic steering system is full-hydraulic steering system. It is a closed loop control system by using the meter motor to realize the hydraulic-internalfeedback. It can simplify the structure of the steering system and decrease the manipulating force of the steering system, which is a good choice for the vehicles with two axles. Actually, it is still belong to Akerman's mechanical linkage steering, and the only difference is its hydraulic assistant force function. Obviously, it can't also realize the steering of the vehicles with more than two axles. Moreover, another defect of it is low efficiency. But at present, the load-sensitive system has been adopted, which is composed of electro-hydraulic proportional pumps and multi-path electro-hydraulic proportional valves (Kemmetmüller, 2007). This technique can improve the efficiency of construction machine to some extent.

c. Based-networked electro-hydraulic steering

In view of the advantages of hydraulic transmission on power transmission as well as the opportunities of network technique on information share and integration, a distributed and numerical manipulating control scheme based on field-bus network and electro-hydraulic proportional control is proposed for motion synthesis and coordinated control of construction machinery with multi-axle driving vehicles. 


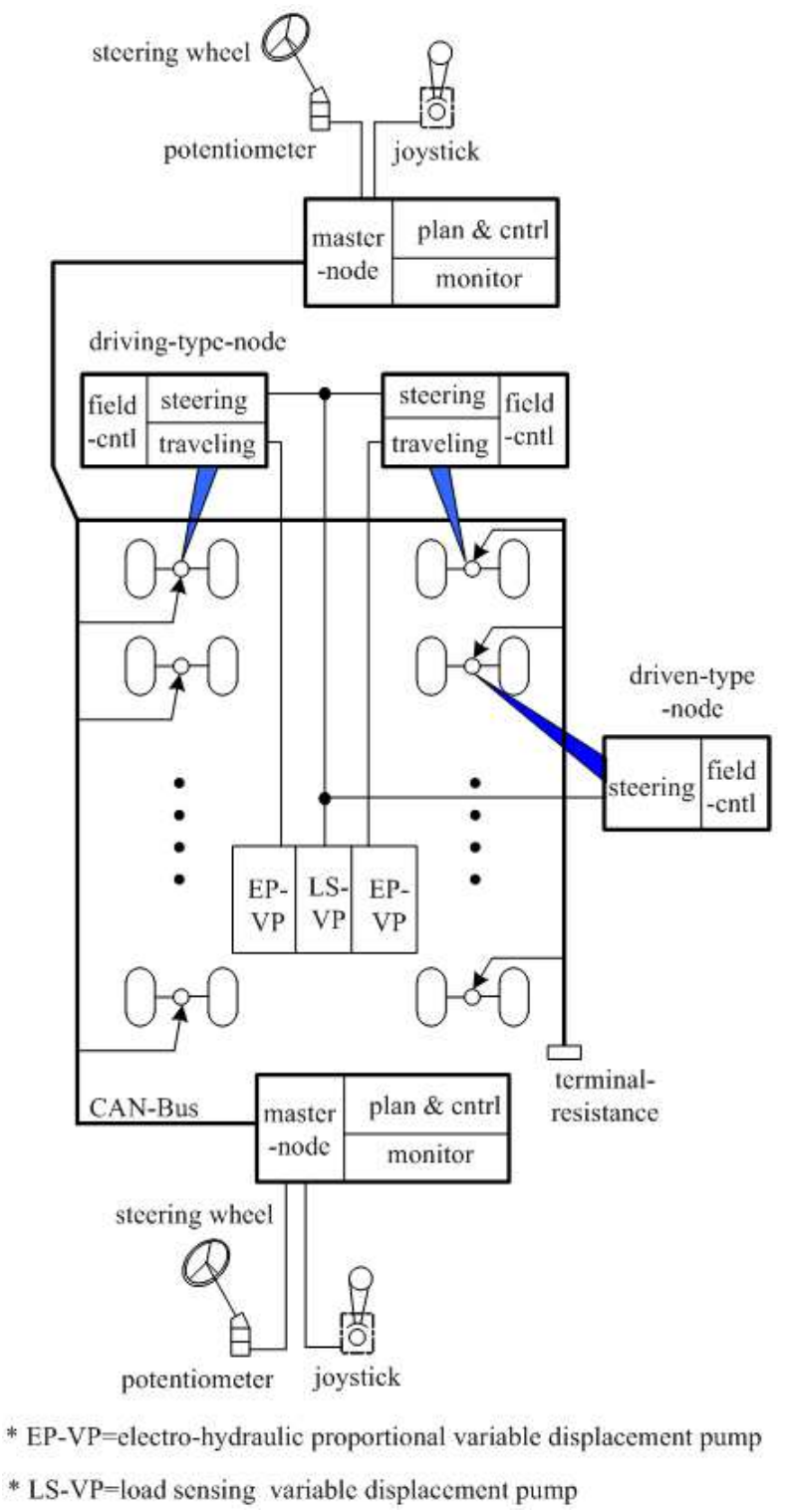

Fig. 6. NCS-based electro-hydraulic steering system

Without loss of generality, this method is applied using the DCY series of transportation vehicle (Li et al., 2007) as the example. The control principle of steering system is shown in Fig. 6. The independent steering mechanism is adopted, i.e. a single axle is driven by a valve-controlled hydraulic cylinder. Each wheel axle can be controlled by intelligent node on the CAN-Open network to turn any angle. In Fig.6, the types of the nodes contain the master controller located in the cab to receive all kinds of operation commands, and the field 
nodes such as driving-type-node and driven-type-node to be placed at the two sides of the vehicle body. Each of them controls several groups of steering, driving and suspending mechanisms. In virtue of software trapezoid (kinematical resolution), this scheme can achieve multiple steering modes such as diagonal steering, longitudinal steering, front (rear) axle steering, and center steering, etc..

The kinematical models of individual steering mode are established in advance and memorized in the master controller. During the running, the expected turning angle of every wheel is resolved from steering wheel in master node according to kinematical model and transmitted to local controller node by bus data exchange. Thus, motion synthesis is implemented through multiple closed-loop controls of steering mechanisms in the same time. In principle, as long as each individual wheel can turn to its expected angle precisely, the whole vehicle can realize the pure rolling steering, in which all axles turn around the rotation center without slipping and sliding.

\section{Kinematics analysis of two-axle driving vehicle}

For convenient comprehension, we firstly analyze the two-axle driving vehicle. As shown in Fig.7, the vehicle has two driving wheels and a driven wheel which can turn any angle. The differential speed steering is employed while traveling. In Fig.7, OXY denotes global coordination and Pxy denotes mobile coordination built on the vehicle reference point $P$. Define the state vector of $(X, Y, \theta)$, where $(X, Y)$ is position coordinate of point $P$ in $O X Y$ and $\theta$ is the driving orientation angle, i.e. the included angle between $x$-axis of $P x y$ and $X$-axis of OXY. The axle space of two driving wheel is $2 B$ and axle-space length between driving wheels and driven wheel is $W$. Suppose the left and right driving wheels' linear speeds are given as $v_{l}$ and $v_{r}$, thus the resultant speed along the $P x$-axis can be get

$$
v_{x}=\frac{1}{2}\left(v_{l}+v_{r}\right)
$$

The turning speed of vehicle is given as

$$
\dot{\theta}=\frac{1}{2 B}\left(v_{r}-v_{l}\right)
$$

Suppose $O^{\prime}$ is turning center and the turning radius $R=\overline{O^{\prime} P}, R$ can be accumulated by differential speed steering relation $v_{l} / v_{r}=(R-B) /(R+B)$, thus

$$
R=\frac{v_{l}+v_{r}}{v_{l}-v_{r}} B=\frac{v_{x}}{\dot{\theta}}
$$

The driven wheel is free wheel here. Its rotation angle $\varphi$ can be obtained.

$$
\varphi=\arctan \frac{W}{R}=\arctan \frac{W\left(v_{r}-v_{l}\right)}{B\left(v_{r}+v_{l}\right)}
$$

The kinematic model of reference point $P$ in OXY coordination can be obtained as 


$$
\left\{\begin{array}{l}
\dot{X}=v_{x} \cos \theta=\frac{1}{2}\left(v_{l}+v_{r}\right) \cos \theta \\
\dot{Y}=v_{x} \sin \theta=\frac{1}{2}\left(v_{l}+v_{r}\right) \sin \theta \\
\dot{\theta}=\omega_{z}=\frac{1}{2 B}\left(v_{r}-v_{l}\right)
\end{array}\right.
$$

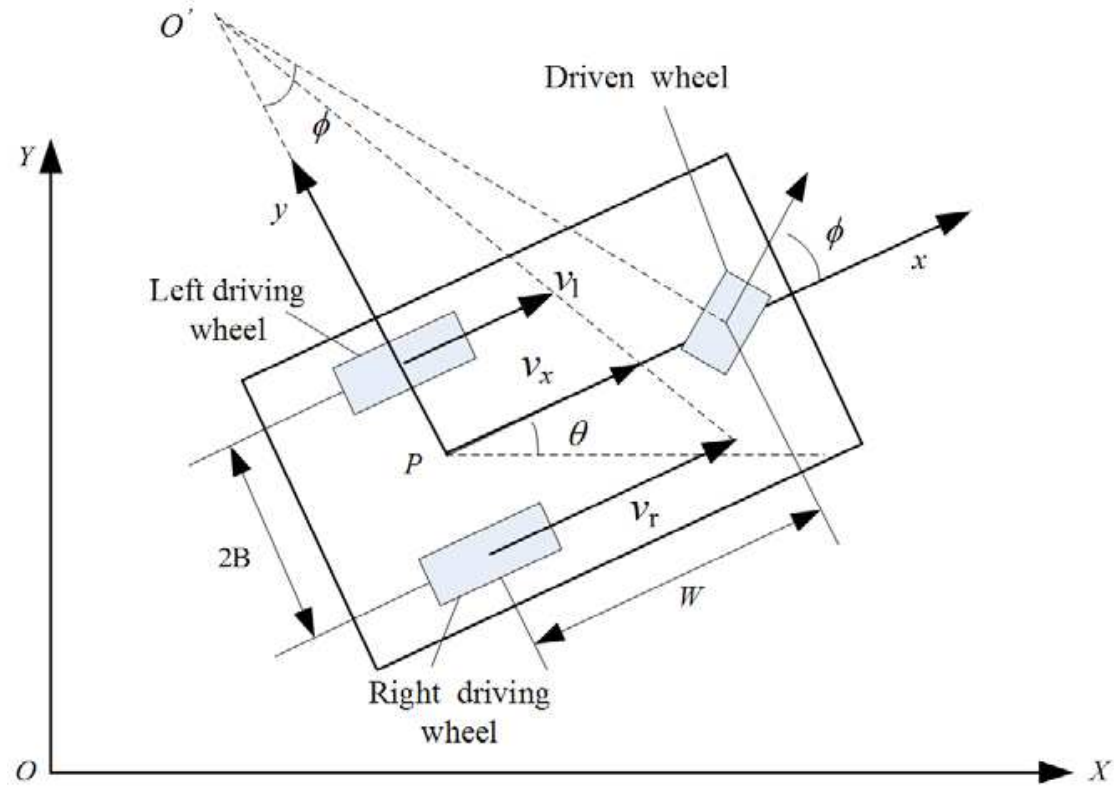

Fig. 7. Kinematic schematic of two-axle driving vehicle

\section{Kinematics analysis of multi-axle driving vehicle}

For multi-axle driving vehicle, independent steering machines are necessary for all wheels including driving wheels and driven wheels to realize the pure rolling around certain center while steering. Taking an eight-wheel vehicle as an example, kinematic schematic is shown in Fig.8. Assume that the vehicle is rotated around point $O^{\prime}$ with steering wheel rotates $\alpha$ at a certain moment. The position coordinate of vehicle center $P$ is $\left(X_{P}, Y_{P}\right)$ and the orientation angle is $\theta$ in global coordination $O X Y$. The rotation angles of wheels are represented as $\varphi_{i}(i=1,2, \ldots, 8)$ relative to $P x$-axis. The linear speeds of all wheels are $v_{i}(i=1,2, \ldots, 8)$ and the traveling speed of vehicle center point $P$ is $V_{P}$. Suppose space lengths between adjacent wheel-axles are equal, denoted as $L$. The left-right direct-axle space is $2 B$. Define the whole vehicle turning radius $R=\overline{O^{\prime} P}$ and each wheel turning radius $R_{i}(i=1,2, \ldots, 8)$ is the length from $O^{\prime}$ to wheel-axle center.

In order to achieve the pure-rolling steering without slipping, the rotation angles $\varphi_{i}$ and linear speeds $v_{i}$ of all wheels must match certain geometrical relation. Let left first wheel 
trace the steering wheel rotation angle, i.e. $\varphi_{1}=\alpha$, thus $R_{1}=1.5 \mathrm{~L} / \sin \varphi_{1}$ and the vehicle turning radiuses can be obtained

$$
R=R_{1} \cos \varphi_{1}+B=1.5 L \cot \varphi_{1}+B
$$

The rotation angles $\varphi_{i}$ should meet the steering trapezium, described as

$$
\left\{\begin{array}{l}
\varphi_{1}=\alpha, \quad \varphi_{4}=-\varphi_{1} \\
\varphi_{2}=\arctan \frac{0.5 L}{(R-B)}, \quad \varphi_{3}=-\varphi_{2} \\
\varphi_{5}=\arctan \frac{1.5 L}{(R+B)}, \quad \varphi_{8}=-\varphi_{5} \\
\varphi_{6}=\arctan \frac{0.5 L}{(R+B)}, \quad \varphi_{7}=-\varphi_{6}
\end{array}\right.
$$

Respective wheel's turning radius is expressed as

$$
R_{i}= \begin{cases}(R-B) / \cos \varphi_{i}, & i=1,2,3,4 \\ (R+B) / \cos \varphi_{i}, & i=5,6,7,8\end{cases}
$$

In the ideal situation, all wheels roll purely around center $O^{\prime}$ in which the linear speeds $v_{i}$ are proportional to relative the turning radiuses $R_{i}$. In this case, the vehicle can be looked as a rigid body rotating around fixed-axis, thus turning velocity can be expressed as $\dot{\theta}=\frac{V_{P}}{R}=\frac{v_{i}}{R_{i}}$. Suppose left first wheel is a driving wheel and its speed $v_{1}$ is given, the vehicle center speed can be get $V_{P}=v_{1} \frac{R}{R_{1}}=v_{1}\left(\cos \varphi_{1}+\frac{B}{1.5 L} \sin \varphi_{1}\right)$. Consequently, the kinematical function of vehicle motion can be depicted as

$$
\left\{\begin{array}{l}
\dot{X}_{P}=V_{P} \cos \theta=v_{1}\left(\cos \varphi_{1}+\frac{B}{1.5 L} \sin \varphi_{1}\right) \cos \theta \\
\dot{Y}_{P}=V_{P} \sin \theta=v_{1}\left(\cos \varphi_{1}+\frac{B}{1.5 L} \sin \varphi_{1}\right) \sin \theta \\
\dot{\theta}=\omega=\frac{V_{P}}{R}=\frac{v_{1} \sin \varphi_{1}}{1.5 L}
\end{array}\right.
$$

Other driving wheels' linear speeds should meet $v_{i}=\omega R_{i}$. During the entire steering procedure, if the actual wheel (axle) turning angles or driving wheels' speeds can't keep matching with their planned values, the pure-rolling condition will not be satisfied. Consequently, the serious slippage of the wheels relative to the ground will be generated, and also the unbalanced force among steering mechanisms will be induced due to the actuation redundancy. 


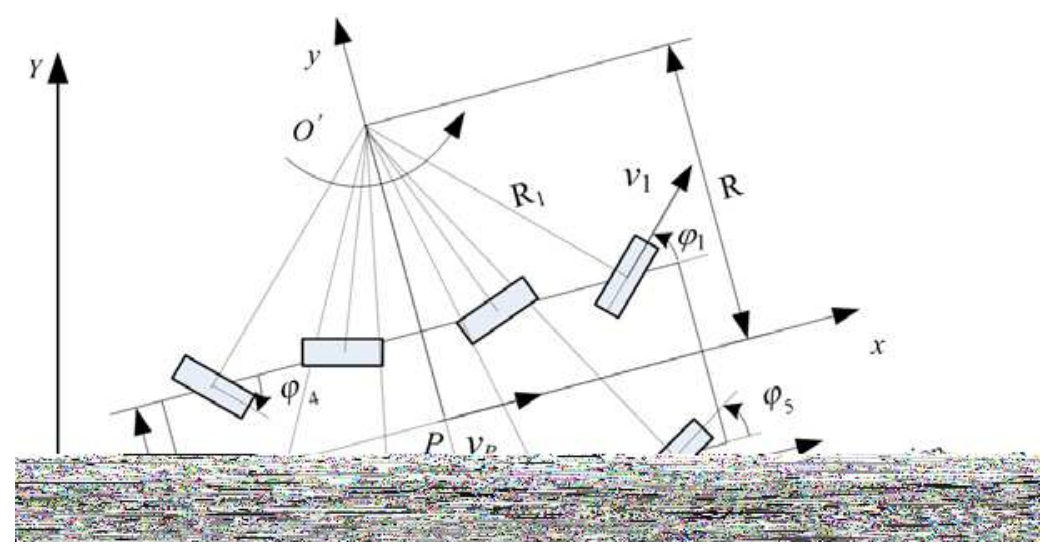

Fig. 8. Kinematic schematic of multi-axle driving vehicle

\section{Hydraulic control of travelling and steering of multi-axle vehicle}

\subsection{Travelling hydraulic system}

Travelling hydraulic system is one typical pump-control-motor system as shown in Fig.9. In general, the closed-type hydraulic circuit with one or two proportional variabledisplacement pumps is adopted and each pump drives multiple parallel variabledisplacement motors to drive the vehicle. This kind of motor can switch between two working conditions of slow speed and large torque as well as high speed and little torque. Through the switch and combination of motors' displacement, three or four speed stages can be formed, and the stepless speed-adjustment in every stage can be achieved by controlling the displacement of pump. As stopping to steer, all wheels can be switched into "free wheel" state. Furthermore, the speed sensors can be installed on the motors to attain closed-loop travelling speed control.

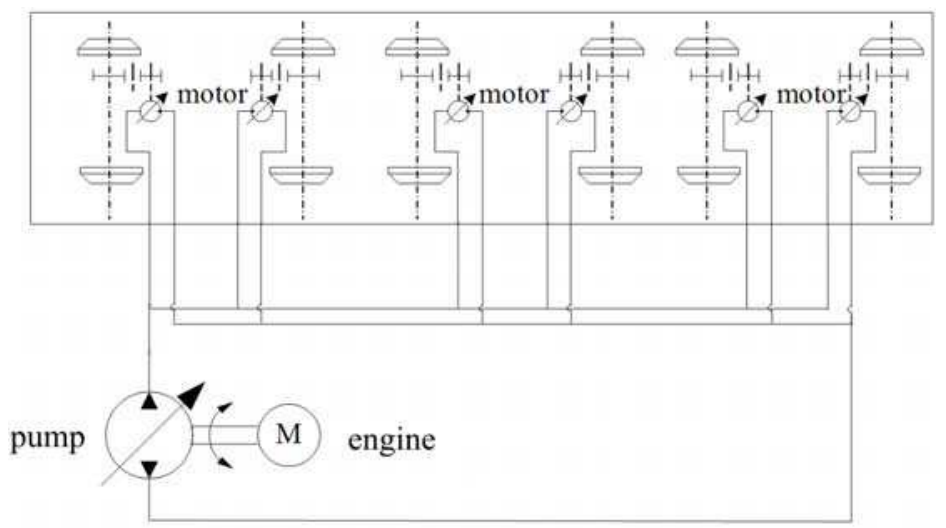

Fig. 9. Travelling hydraulic system schematic 


\subsection{Steering hydraulic system}

According to the dynamic analysis in the steering procedure, when the velocity of the vehicle is low and the lateral slip angle is very small, the steering belongs to natural steering (Hosaka, 2004). In this case, the rotational dynamic influence to the vehicle chassis can be omitted. The whole steering motion is governed by the dynamic equations of each wheel. As shown in Fig. 10, a single wheel's steering hydraulic system contains proportional amplifier components, a valve-controlled cylinder, and the steering linkage mechanism.

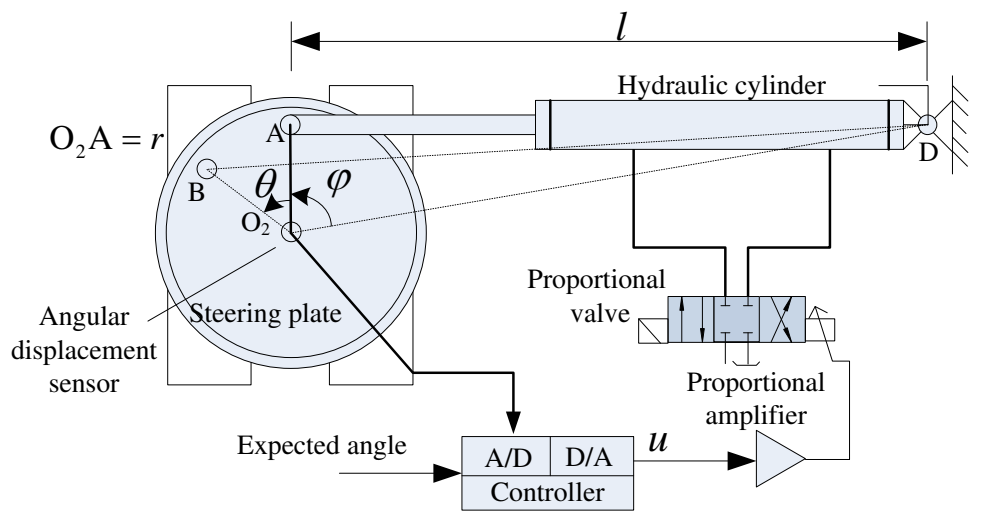

Fig. 10. Steering hydraulic system schematic

In light of the hydraulic work principles and taking $u$ and $\theta$ as the control input and output of the independent steering mechanism, we obtained the following governing equation.

$$
\left\{\begin{array}{l}
\left(k_{\mathrm{v}} \frac{u}{u_{\mathrm{m}}}\right) \sqrt{1-\operatorname{sgn}\left(\frac{u}{u_{\mathrm{m}}}\right) \frac{p_{\mathrm{L}}}{p_{\mathrm{s}}}}=A_{r} r(\theta) \dot{\theta}+\frac{V_{t}}{4 \beta_{e}} \dot{p}_{\mathrm{L}}+C_{a} p_{\mathrm{L}} \\
p_{\mathrm{L}} A_{r} r(\theta)=J \ddot{\theta}+B_{m} \dot{\theta}+T_{\mathrm{L}} \operatorname{sgn}(\dot{\theta}) \\
r(\theta)=\frac{r \sqrt{l^{2}+r^{2}} \sin (\theta+\varphi)}{\sqrt{l^{2}+2 r^{2}+2 r l \sin \theta-2 r^{2} \cos \theta}} \\
T_{\mathrm{L}}=2 Z \xi \sqrt{B_{0}^{2} / 4+b^{2} / 8}
\end{array}\right.
$$

where $r(\theta)$ represents the equivalent arm of the cylinder's thrust force applied onto the turn-plate. This function is deduced from the geometric relationship of turn-plate and the cylinder. Since the movement of the piston within its stroke does not result in significant changes of the moment of the cylinder's thrust force, we consider it as a constant in order to simplify the analysis. The notations of the symbols are listed in Table 1.

\section{Multi-axles motion synthesis and coordinated control}

For multi-axle driving vehicles, the motion synthesis and coordinated control problem occurs in the steering procedure while travelling. The wheel-axles turning angles are expected to satisfy the pure-rolling condition described by Eqn. (10). However, affected by 
many factors, the actual wheel (axle) turning an 
concept has been developed and widely used in multi-axle motion synthesis such as reducing contouring error of $\mathrm{CNC}$ machines (Zhong,2002) and contour tracking control of mobile robot (Sun,2002; Rodriguez \& Nijmeijer, 2004). Here, a simple PID cross-coupled controller based on real-time feedback and information sharing is presented to resolve the synchronization problem of multi-axle vehicle while steering. The basic idea is to select one wheel's actual turning angle as reference and the relative angles of the other wheels are solved from the motion equations. The tracking and contouring errors of each wheel can be obtained by comparing its actual feedback value with its two expected ones from steering wheel and fiducial wheel. Then, two closed-loop PID control laws are designed respectively for the contouring error and the tracking error. As a result, the controller can satisfy coherence demand of contour tracking in the process of steering. This control method with contour error tracking of single-axle is illustrated in Fig.12.

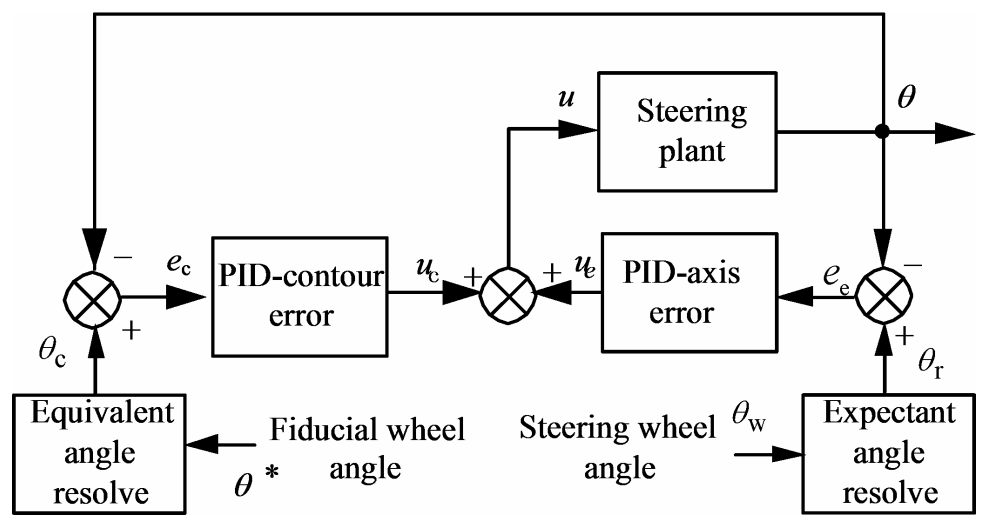

Fig. 12. Block diagram of the steering controller with contouring error

In Fig.12, the output of each axle needs to meet two requirements. One is the expected angle $\theta_{\mathrm{r}}$ resolved from the steering wheel command, and the other is the theoretically equivalent angle $\theta_{\mathrm{c}}$ resolved from the current feedback value of the angle of fiducial wheel. As a result, the tracking error and contouring error are expressed as $e_{\mathrm{e}}=\theta_{\mathrm{r}}-\theta$ and $e_{\mathrm{c}}=\theta_{\mathrm{c}}-\theta$. The corresponding control law is composed of two parts, i.e., $u=u_{\mathrm{e}}+u_{\mathrm{c}}$. The piecewise PID control law is adopted in $u_{\mathrm{e}}$ and $u_{\mathrm{c}}$. The expressions of the control law $u_{\mathrm{e}}$ and $u_{\mathrm{c}}$ are respectively given by:

$$
\begin{gathered}
u(k)=u_{\mathrm{e}}(k)+u_{\mathrm{c}}(k) \\
u_{\mathrm{e}}(k)=u_{\mathrm{e}}(k-1)+P_{\mathrm{e}}\left(e_{\mathrm{e}}(k)\right) \Delta e_{\mathrm{e}}(k)+I_{\mathrm{e}}\left(e_{\mathrm{e}}(k)\right) e_{\mathrm{e}}(k)+D_{\mathrm{e}}\left(e_{\mathrm{e}}(k)\right) \Delta^{2} e_{\mathrm{e}}(k) \\
u_{\mathrm{c}}(k)=u_{\mathrm{c}}(k-1)+P_{\mathrm{c}}\left(e_{\mathrm{c}}(k)\right) \Delta e_{\mathrm{c}}(k)+I_{\mathrm{c}}\left(e_{\mathrm{c}}(k)\right) e_{\mathrm{c}}(k)+D_{\mathrm{c}}\left(e_{\mathrm{c}}(k)\right) \Delta^{2} e_{\mathrm{c}}(k)
\end{gathered}
$$

where $P_{i}\left(e_{i}(k)\right), I_{i}\left(e_{i}(k)\right)$, and $D_{i}\left(e_{i}(k)\right)(i=\mathrm{e}, \mathrm{c})$ respectively denote the function of proportional gain, integral gain, and differential gain of $u_{\mathrm{e}}$ and $u_{\mathrm{c}}$ with $\Delta e_{i}(k)=e_{i}(k)-e_{i}(k-1)$, and $\Delta^{2} e_{i}(k)=\Delta e_{i}(k)-\Delta e_{i}(k-1)$. 
Note that the method to solve the contouring error is based on the transformation to the reference angle. Hence, we can change the contouring tracking problem to a synchronized tracking problem. The mathematical relationship between the contouring error and the tracking error can be readily depicted from Fig. 13. Here, $x_{1}$ is the equivalent angle based on the steering kinematics formula from fiducial wheel's angle, $x_{2}$ denotes the real steering angle of the discussed axle, and $\overline{P R}$ and $\overline{P C}$ denote the tracking error and the contouring error respectively. Because $e_{\mathrm{c}}=\overline{P C}=\overline{B P} \cos (\pi / 4), \overline{B P}$ can be used to express the contouring error. Obviously, through this transformation, the contouring tracking problem can be converted to a synchronized tracking problem so that the computation of the contouring error is simplified.

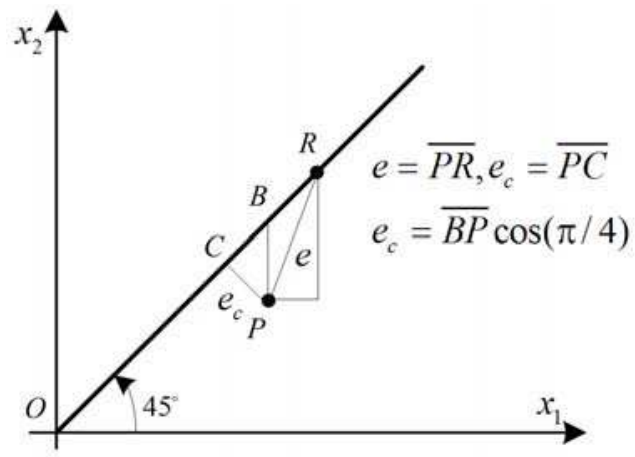

Fig. 13. Simplification of contouring error

\section{Manipulating control of the multi-axle-electrohydralic-control-transpoter}

The DCY series of transportation vehicles are designed and commissioned to transfer huge and heavy objects. Such a vehicle, integrated with electro-hydraulic proportional control and networked control, has multiple functions such as travelling, steering, leveling, and lifting. In order to reduce the supporting load on each of the vehicle wheels, a number of supporting and driving wheels are employed. Without loss of generality, the following study is carried out using the DCY270 model as the example.

\subsection{Overall framework design of control system}

As shown in Fig. 14, the DCY270 transportation vehicle is designed to carry 270 tons load for building industry and ship manufacturing. It has 10 axles and 20 wheels that can steer in multiple modes. An integrated solution approach based on the NCS (through the field-bus with CAN-Open protocols) and distributed electro-hydraulic proportional control is proposed to perform various functions. The control principle of steering system is shown in Fig.15. There are three intelligent nodes on the CAN-Open network. The CC node is the master controller located in the cab to receive all kinds of operation commands. $\mathrm{C} 1$ and $\mathrm{C} 2$ nodes represent the two controllers placed at the two sides of the vehicle body. Each of them controls four groups of steering, driving and suspending mechanisms close to it. Fig.15 (a) shows the steering mechanism of a single axle driven by a valve-controlled hydraulic cylinder, while Fig.15 (b) shows the configuration of the CC. 


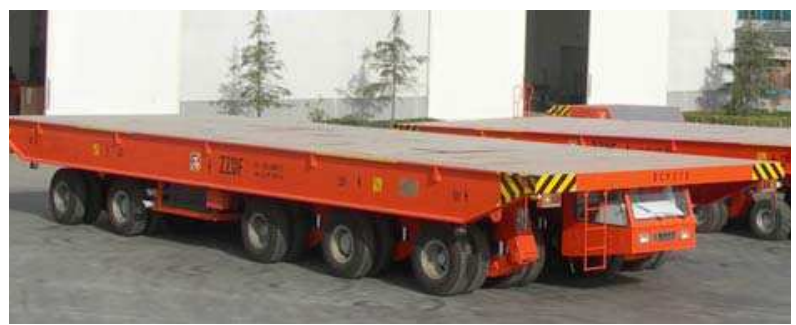

Fig. 14. DCY 270 powered transportation vehicle

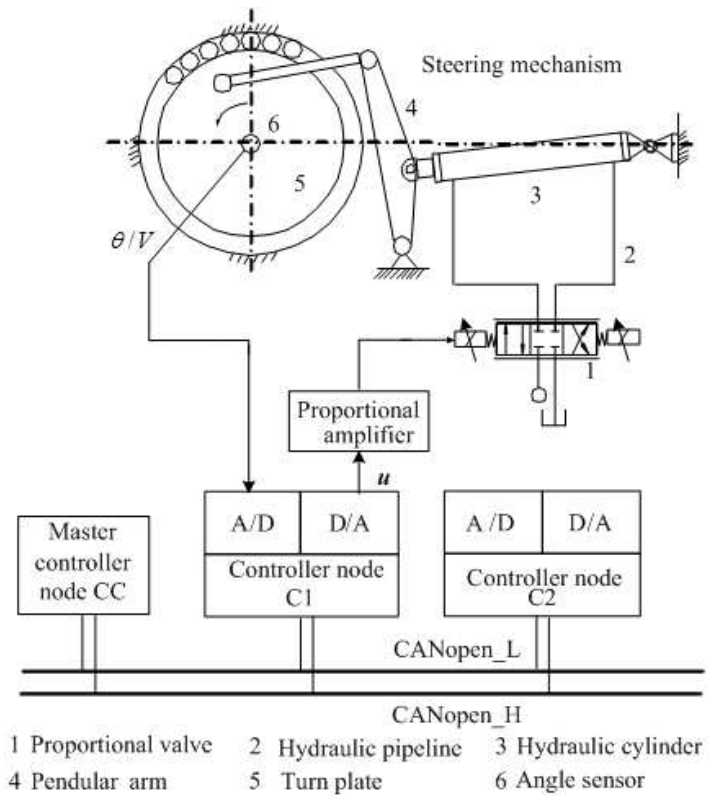

(a). Diagram of the steering system based on CAN-bus

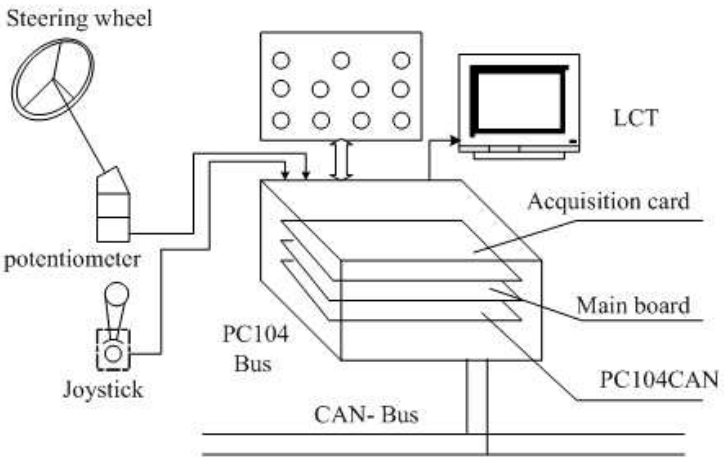

(b). Configuration of the master/slave controller node

Fig. 15. NCS-based electro-hydraulic control diagram for steering system 


\subsection{Multimode steering system based on NCS}

In order to perform different operation tasks, the transportation vehicle is required to steer in multiple steering modes such as diagonal steering, longitudinal steering, front (rear) axle steering, and center steering (as shown in Fig.16). According to this figure, the steering kinematics models under different steering modes can be formulated. In principle, as long as each individual wheel can turn to its expected angle precisely, the whole vehicle can realize different steering modes, in which all axles turn around the rotation center without slipping and sliding, i.e., a pure rolling steering.

Obviously, the traditional Ackerman's steering trapezium can only be employed for the simple steering. Moreover, the design and manufacture of the steering linkage mechanism are difficult and costly. However, the networked-control provides an effective way to realize multimode steering.

Here, we give out the kinematic model of the normal steering (longitudinal steering) mode as shown in the up-right corner of Fig. 16. The rotation angles of left and right five axles are set as $\alpha_{i}$ and $\beta_{i}(i=1,2, \cdots, 5)$ respectively. The notations of $B, L_{1}, L_{2}, L_{3}$ and $R$ are shown in Fig. 16. In terms of forward traveling direction, positive and negative turnings are identified with counterclockwise and clockwise directions, respectively. $\alpha_{1}$ is controlled by the rotational angle of the steering wheel $\theta_{\mathrm{w}}$, while other axles' expected angles are calculated from the given motion relationship. The expected angle of each axle is as follows.

$$
\left\{\begin{array}{l}
\alpha_{1}=i_{\mathrm{w}} \theta_{\mathrm{w}}, \\
R=0.5\left(L_{1} \cot \alpha_{1}+B\right), \tan \alpha_{2}=0.5 L_{2} /(R-0.5 B), \\
\tan \alpha_{3}=0.5 L_{3} /(R-0.5 B), \tan \beta_{1}=0.5 L_{1} /(R+0.5 B), \\
\tan \beta_{2}=0.5 L_{2} /(R+0.5 B), \tan \beta_{3}=0.5 L_{3} /(R+0.5 B), \\
\alpha_{2}=-\alpha_{4}, \alpha_{1}=-\alpha_{5}, \beta_{2}=-\beta_{4}, \beta_{1}=-\beta_{5}
\end{array}\right.
$$

where $i_{\mathrm{w}}$ is the transmission ratio between $\alpha_{1}$ and $\theta_{\mathrm{w}}$.

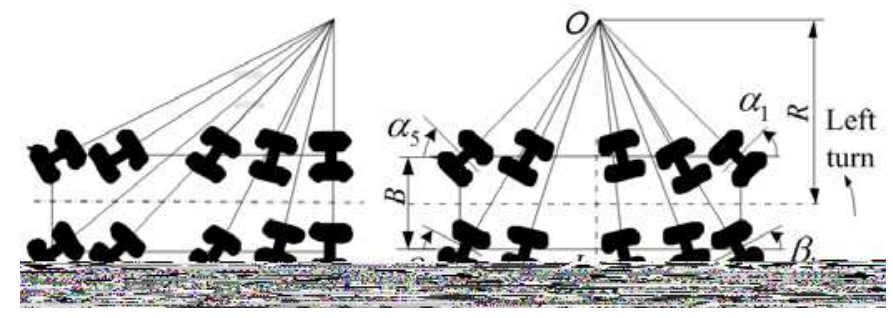

Fig. 16. Kinematics diagrams of different steering modes 
Using the same method, the kinematics models of the other three kinds of steering modes, i.e., front (rear) axle steering, diagonal steering, and center steering, are given in (19), (20) and (21), respectively as follows.

$$
\begin{gathered}
\left\{\begin{array}{l}
\alpha_{5}=i_{\mathrm{w}} \theta_{\mathrm{w}}, R=L_{1} \cot \alpha_{5}+0.5 B, \\
\tan \alpha_{4}=0.5\left(L_{1}+L_{2}\right) /(R-0.5 B), \\
\tan \alpha_{3}=0.5\left(L_{1}-L_{3}\right) /(R-0.5 B), \\
\tan \alpha_{2}=0.5\left(L_{1}-L_{2}\right) /(R-0.5 B), \\
\alpha_{1}=0, \beta_{1}=0, \cot \beta_{5}-\cot \alpha_{5}=2 B / L_{1}, \\
\cot \beta_{4}-\cot \alpha_{4}=2 B /\left(L_{1}+L_{2}\right), \\
\cot \beta_{3}-\cot \alpha_{3}=2 B /\left(L_{1}-L_{3}\right), \\
\cot \beta_{2}-\cot \alpha_{2}=2 B /\left(L_{1}-L_{2}\right) .
\end{array}\right. \\
\qquad \begin{array}{l}
\tan \alpha_{1}=-\beta_{1}=i_{\mathrm{w}} \theta_{\mathrm{w}}, i=1,2,3,4,5 \\
\tan \beta_{1}=L_{1} / B, \tan \alpha_{2}=-L_{2} / B, \tan \alpha_{3}=-L_{3} / B, \tan \beta_{3}=L_{3} / B
\end{array} \\
\alpha_{1}=-\alpha_{5}, \quad \alpha_{2}=-\alpha_{4}, \quad \beta_{2}=-\beta_{4}, \quad \beta_{1}=-\beta_{5}
\end{gathered}
$$

Note that for the centre steering mode, the driving motors in the left and right sides are controlled by two pumps respectively. As a result, the center steering in the same direction can be achieved.

\subsection{Motion synthesis strategy for contouring control}

For the steering system of the DCY270 transportation vehicle, above cross-coupling PID control algorithm is adopted and the detailed resolution is given as follows. The ten wheels (axles) are divided into two groups: $\alpha_{1} \sim \alpha_{5}$ and $\beta_{1} \sim \beta_{5}$ controlled by $\mathrm{C} 1$ and $\mathrm{C} 2$, respectively. One wheel is selected as the norm of each group, i.e. $\alpha_{1}$ and $\beta_{5}$. At the same time $\alpha_{1}$ is sent to $\mathrm{C} 2$ as $\beta_{5}{ }^{\prime}$ s norm through CAN-bus from C1. Taking longitudinal steering as an example, the task of resolving the expected angles can be carried out by the master control node CC according to (18), such that $\bar{\alpha}_{1}=i_{\mathrm{w}} \theta_{\mathrm{w}}, \bar{\alpha}_{1} \rightarrow \bar{\alpha}_{2} \sim \bar{\alpha}_{5}$, and $\bar{\alpha}_{1} \rightarrow \bar{\beta}_{1} \sim \bar{\beta}_{5}$. Here, we use the operator $\rightarrow$ to indicate that the right terms are determined from the left known term. Equivalent angles are computed from real feedback $\alpha_{1}$ according to (18), which can be expressed as $\alpha_{1} \rightarrow \hat{\alpha}_{2} \sim \hat{\alpha}_{5}, \alpha_{1} \rightarrow \hat{\beta}_{5}$, and $\beta_{5} \rightarrow \hat{\beta}_{1} \sim \hat{\beta}_{4}$. Then we can obtain the tracking errors: $e_{i}=\bar{\alpha}_{i}-\alpha_{i}$, or $e_{i}=\bar{\beta}_{i}-\beta_{i}(i=1,2, \ldots, 5)$ with $e_{\mathrm{e} i}=e_{i}$, and the contouring error: $e_{c i}=\hat{\alpha}_{i}-\alpha_{i}$ or $e_{c i}=\hat{\beta}_{i}-\beta_{i}(i=1,2, \ldots, 5)$. Each node's closed-loop control is formed by two control components $u_{\mathrm{e}}$ and $u_{\mathrm{c}}$. The tracking error and contouring error can be restrained by using the piecewise PID control law described in (15)-(17). In the practical application, the magnitude of the control signal is restricted in a suitable range according to the specification of the driving equipments and control targets. The expressions of the control signal and the PID parameters are given. 


$$
\begin{gathered}
u(k)= \begin{cases}u_{\mathrm{max}} \operatorname{sgn}(e(k)) & |e(k)|>\delta_{1} \\
u(k) & \xi_{1}<|e(k)| \leq \delta_{1} \\
u(k-1) & |e(k)| \leq \xi_{1}\end{cases} \\
\left\{P_{\mathrm{e}}, I_{\mathrm{e}}, D_{\mathrm{e}}\right\}= \begin{cases}\left\{p_{\mathrm{e} 1}, i_{\mathrm{e} 1}, d_{\mathrm{e} 1}\right\} & \xi_{1}<|e(k)| \leq r_{1} \\
\left\{p_{\mathrm{e} 2}, i_{\mathrm{e} 2}, d_{\mathrm{e} 2}\right\} & r_{1}<|e(k)| \leq \delta_{1}\end{cases} \\
\left\{P_{\mathrm{c}}, I_{\mathrm{c}}, D_{\mathrm{c}}\right\}= \begin{cases}\left\{p_{\mathrm{c} 1}, i_{\mathrm{c} 1}, d_{\mathrm{c} 1}\right\} & \xi_{2}<\left|e_{\mathrm{c}}(k)\right| \leq r_{2} \\
\left\{p_{\mathrm{c} 2}, i_{\mathrm{c} 2}, d_{\mathrm{c} 2}\right\} & r_{2}<\left|e_{\mathrm{c}}(k)\right| \leq \delta_{2}\end{cases}
\end{gathered}
$$

where, $0<\xi_{1}<r_{1}<\delta_{1}, 0<\xi_{2}<r_{2}<\delta_{2}$. The saturation values and dead zone of control signal are decided according to the actual case. In view point of the practical requests of the system, the rapidity is not important but the static error and overshoot should be avoided. Relying on such control requirements, the piecewise PID parameters are estimated by empirical values and further optimized in practical tests.

Combining the kinematical model and steering control law with the dynamic model of electro-hydraulic steering mechanism, the block diagram of the overall vehicle steering system is shown in Fig.17.

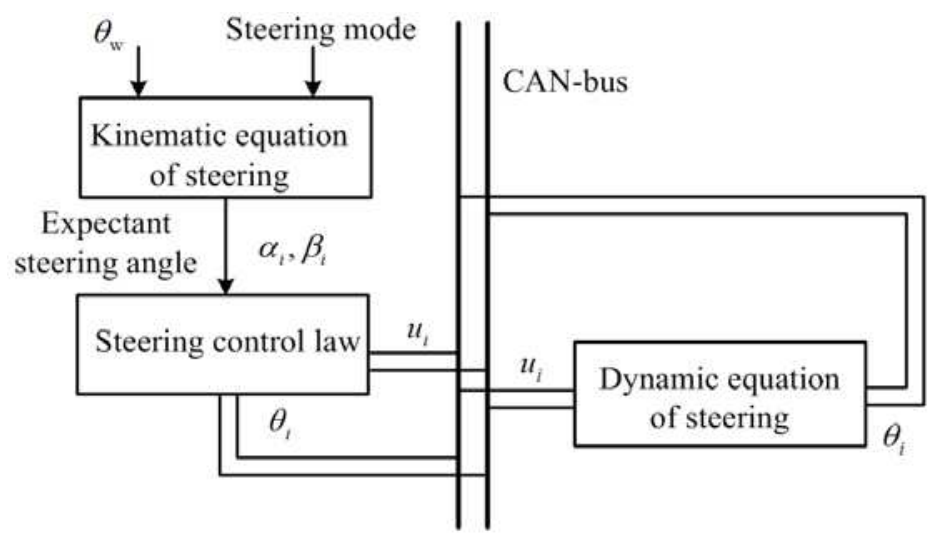

Fig. 17. Block diagram of the overall steering system

\subsection{Experiments}

The test of center steering, diagonal steering and longitudinal steering are performed and actual effects are shown in Fig. 18 In the longitudinal steering control, the cross-coupled control law is adopted and the contouring errors of left-right symmetrical wheel 2, 4, 7, 9 are measured and drawn as in Fig.19. The result indicates whole vehicle's contouring precise satisfies the manipulation performance demand. 

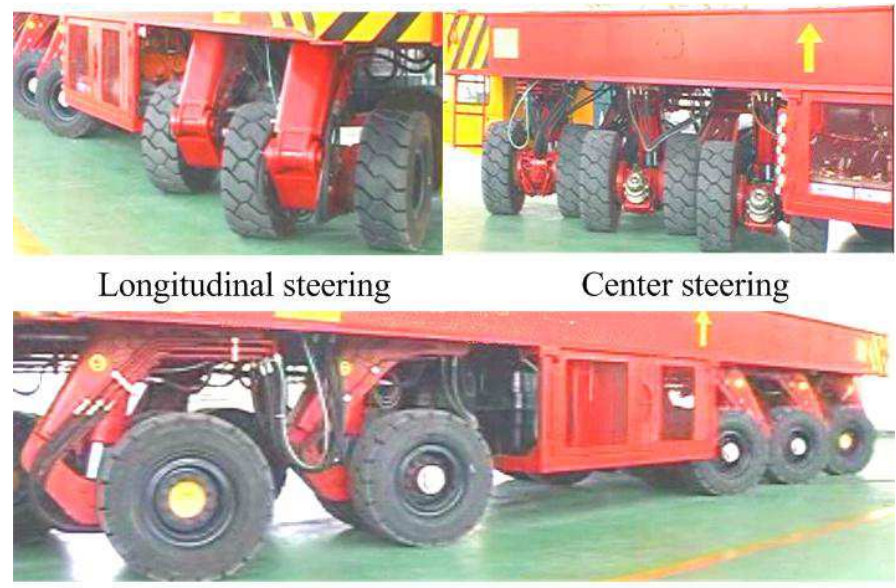

Diagonal steering

Fig. 18. Test of multimode steering

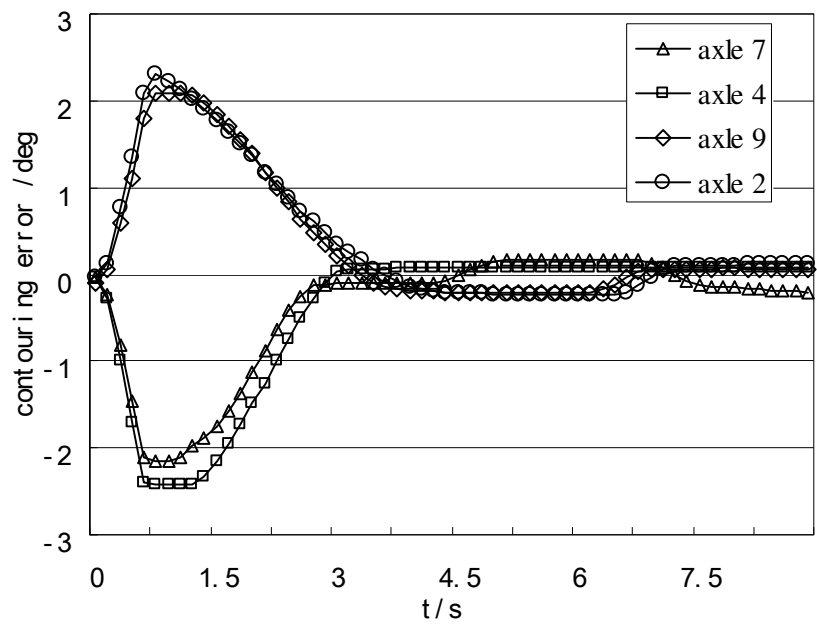

Fig. 19. Experimental result of cross-coupled control law

\section{Manipulating control of track-laying-machinery for high speed railway}

The high-speed railway rail-laying vehicles is one kind of large special automatic machine developed to pave the sleepers and long rails on the new lines so as to satisfy the demands of high speed railway with seamless lines (Zhao et al., 2006). Automatic drive function of rail-laying vehicles can make it follow the scheduled route and control running speed automatically. It is very important to ensure the precision of paving railway lines.

\subsection{Framework of automatic drive system}

Shown as in Fig.20, the rail-laying vehicle consists of guided pedrails, bodywork and power bogies. It is one special type of multi-axle driving vehicle. Guided pedrails and power 
bogies provide traction, bodywork connects guided pedrails by swing assembly, and the steering structure is articulated. Vehicles' automatic drive includes speed control and steering control.

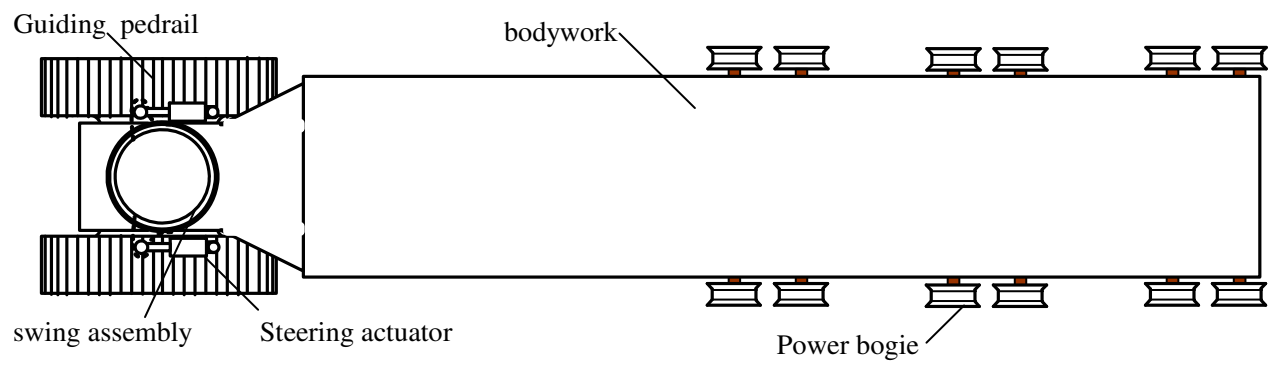

Fig. 20. Structure schematic of rail-laying vehicle

The travelling hydraulic system of rail-laying vehicles is composed of the hydraulic system of guided pedrails and power bogie. They all employ hydrostatic pressure transmission in closed circuit and high-speed driving scheme containing variable stroke pump, variable motor and reduction box. The design works of travelling control focus on the speed synchronism and allocating fraction between guided pedrails and power bogies.

The steering hydraulic system is mounted on guided pedrails. Its main components include proportional valve, two steering hydraulic-cylinders and swing assembly. Automatic steering control system consists of controller, ultrasonic sensors, angular coder, hydraulic steering mechanism.

In consideration of the structure characteristic and control demands, the control system adopts the scheme of electro-hydraulic proportional control system based on network combining CAN-bus network to control separate actuators such as valves, pumps and motors. The configuration and interfaces of control systems are showed in Fig 21. Hardware platform contains integrative IPCs, Fieldbus controllers and sensors. EPEC controller of Finland Company is chosen as Field bus controller. It provides digital input/output, analog input/output and PWM output, which can replace proportional amplifier to drive valve directly. Four EPEC control modules and one IPC are networked by CAN protocol.

\subsection{Steering control system}

The steering mechanism is articulated on the guided pedrail by swing hydraulic-cylinders. Swing cylinders keep or change the comparative angle between padrail and bodywork vehicle to make rail layer move on straight line or curve with different radius. Fig.22 shows the hydraulic steering working principle.

Rail-laying vehicle follows straight line along the indicating route during laying rail to realize automatic guide. Considering the disturbing affection of light, fog, and rain in field, shoe ultrasonic sensor is selected to measure the distance between the line and pedrail. If vehicle deviate the datum line, the shoe ultrasonic sensor can reflect the deviation. At same time, one rotation coder installed in the pedrail panel can measure the current steering angle. These two signals are feedbacked to controller through CANbus, and then controller executes the corresponding algorithm to drive cylinders to correct the travelling direction of the pedrail. Fig.23 is automatic steering control block diagram. 


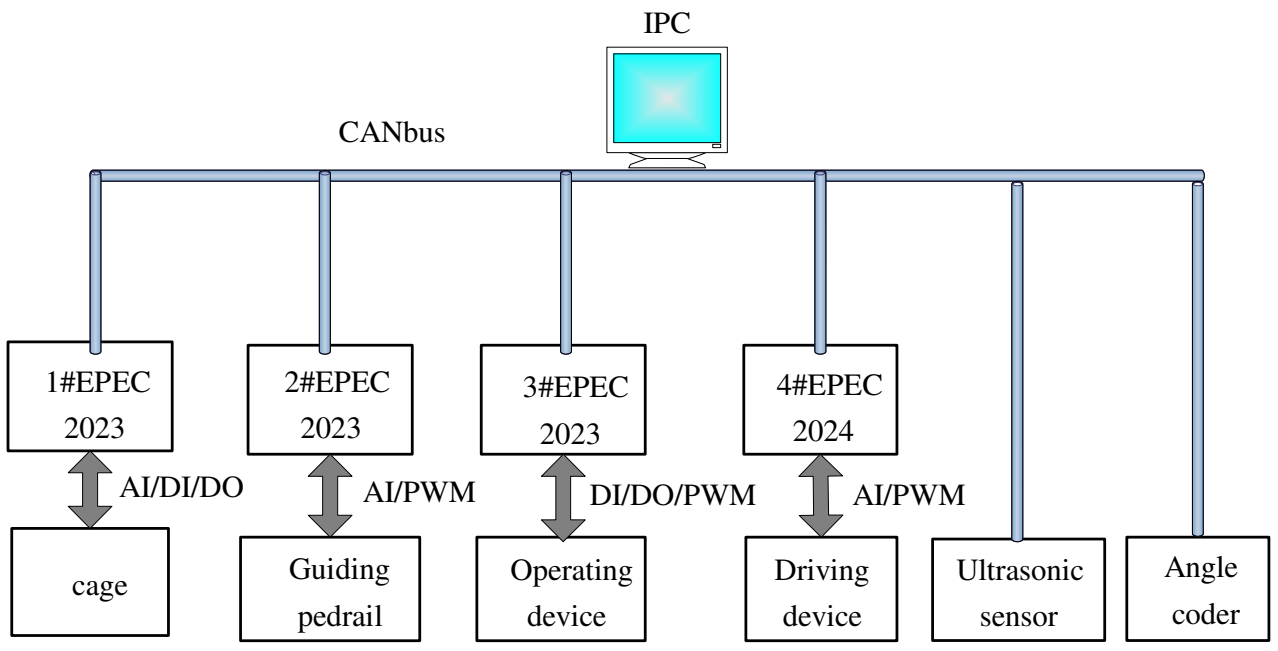

Fig. 21. Configuration of automatic control system

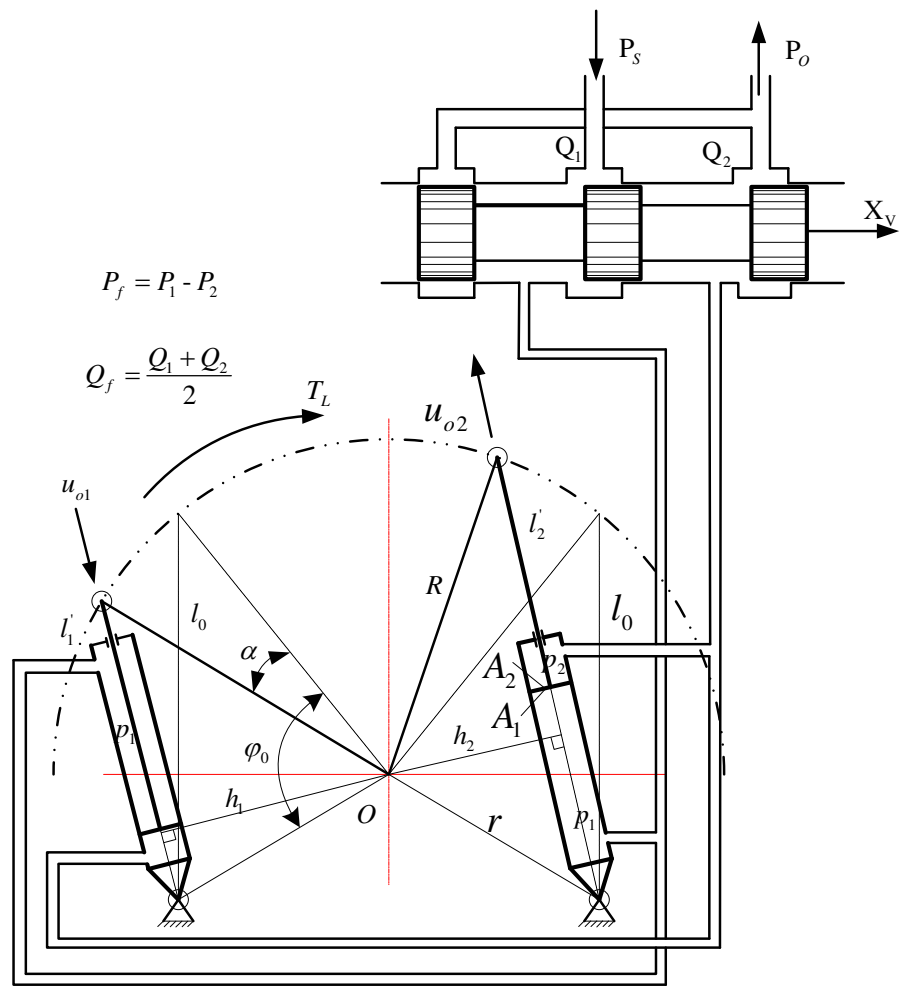

Fig. 22. Hydraulic steering system schemes 


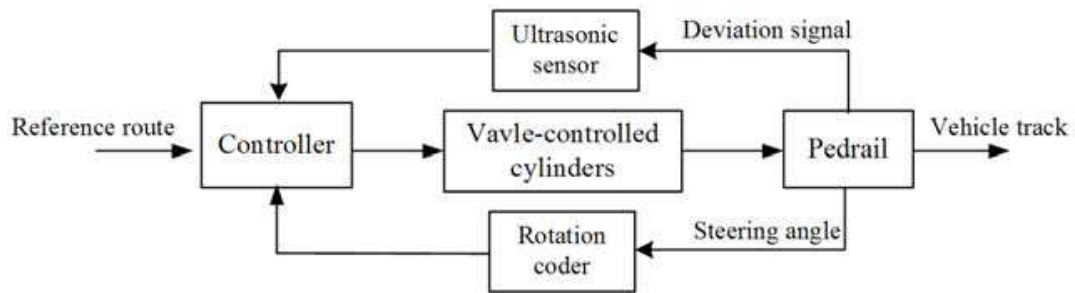

Fig. 23. Automatic steering control block diagram

\subsection{Travelling control system}

The traction is generated by both pedrail vehicle and power bogie. Their travelling hydraulic systems employ hydrostatic pressure transmission in closed circuit and highspeed drive scheme. Two variable pumps respectively drive six motors of three power bogies and two motors of pedrail. The hydraulic system working pressure is $27 \mathrm{MPa}$ and peak pressure is $30 \mathrm{MPa}$. Four speed stages can be switched by controlling the number of working motors and displacement of motors, and the stepless speed-adjustment in every stage can be realized by adjusting the displacement of pump. Of course, the speed sensors are adopted to achieve speed closed-loop control shown as in Fig.24.

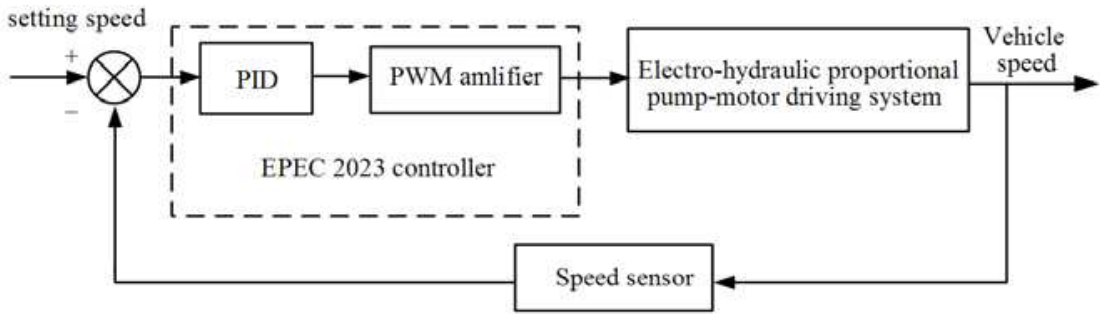

Fig. 24. Schematic diagram of closed-cycle speed control

Because pedrail and power bogies have independent drive systems, the synchronism of pedrail and three power bogies is very important while travelling. The synchronous solution depends on the principle "Power bogie is priority and pedrail is assistant". The controller observes the system pressure and motor rotation speed, and adjust the displacements of the pumps and motors to ensure the travelling synchronization between pedrail chassis and power bogies referring to the speed of power bogies wheel and load change. Six motors of power bogies are synchronous naturally for cohering effect between wheels and rails.

Allocating traction appropriately is essential to ensure system efficiency. Both work condition and load may change while travelling, but those will all reflect in load change. As a result, the displacements of pedrail motors and bogies motors are adjusted relying on load condition to ensure the best allocation of traction between pedrail and bogies.

\section{Conclusion}

Focusing on the problems on the motion synthesis and coordinated control of multi-axle driving vehicles, we have proposed the realization framework based on networked control, and have established the mathematic model of multi-mode-steering kinematics. Then, a kind of the coordinated control method for multi-axle driving vehicles has been studied. 
This study has resulted in the successful development of three kinds of typical heavy construction field robots, i.e. DCY900 transporter, Hoisting-girder transporter with 900t load, and DPG500 high-speed railway rail-laying vehicles.

\section{References}

Hespanha, J.; Naghshtabrizi, P. \& Xu, Y. (2007) A survey of recent results in networked control systems, Proceedings of the IEEE, Vol.95 No.1 pp.138-162

Kemmetmüller, W. (2007). Mathematical modelling and nonlinear controller design for a novel electro-hydraulic power steering system, IEEE/ASME Trans. Mechatron., Vol. 12, No.1, pp. 85-97

Lian, F.; Moyne, J. \& Tibury, D. (2002). Network design consideration for distributed control systems, IEEE Trans. Contr. Syst. Technol., Vol.10, No.2, pp. 297-307

Li, Y.; Yang, G. (2005). Investigation on network control for control and manipulating system of the vehicle and construction machinery, Engineering Science, Vol. 7, No.9, pp. 25-29

Li, Y.;Yang, L., \& Yang, G. (2007). Network-based coordinated motion control of large-scale transportation vehicles. IEEE/ASME Trans. Mechatron., Vol. 12, No.2, pp208-215

Niu, W.; Tomizuka, M. (2001). A new approach of coordinated motion control subjected to actuator saturation, ASME J. Dyn. Syst., Meas., Control, Vol.123, No.3, pp. 496-504

Rodriguez, A.; Nijmeijer, H. (2004). Mutual synchronization of robots via estimated state feedback: a cooperative approach, IEEE Trans. Contr. Syst. Technol., Vol. 12, No. 4, pp. 542-554

Sun, H.; George T. (2002). Motion synchronization for dual-cylinder electrohydraulic lift systems, IEEE/ASME Trans. on Mechatronics, Vol.7, No.2, pp.171-181

Sun, D.; Mills (2002). Adaptive synchronized control for coordination of multi-robot assembly tasks, IEEE Trans. Robot. Autom., Vol. 18, No.4, pp. 498-510

Tomizuka, M.; Hu, J. \& Chiu, T. (1992). Synchronization of two motion control axes under adaptive feedforward control, ASME J. Dyn. Syst.,Meas., Contr., Vol. 114, No. 2, pp. 196-203

Yang, L.; Guo, Z. \& Li, Y. (2009). Posture measurement and coordinated control of twin hoisting-girder transporters based on hybrid network and RTK-GPS, IEEE/ASME Transactions on Mechatronics, Vol.14, No.2, pp.141-150

Yeh, S.; Hsu, P. (2002). Estimation of the contouring error vector for the cross-coupled control design, IEEE/ASME Trans. Mechatronics, Vol. 7, No. 1, pp. 44-51

Yeh, S.; Hsu, P. (2003). Analysis and design of integrated control for multi-axis motion systems, IEEE Transactions on Control Systems Technology, Vol.11, No.3, pp.375-382

Zhong, Q.; Shi, Y. \& Mo, J. (2002). A linear cross coupled control system for high speed machining, Int. J. Adv. Manuf. Technol., Vol. 19, pp. 558-563

Zhao, Y.; Li, Y. \& Yang, L. (2006). Research on automatic drive technology of high-speed railway rail-laying vehicles, IEEE International Conference on Robotics, Automation and Mechatronics, Thailand, June , 2006

Hosaka, M. (2004). Yaw rate control of electric vehicle using steering-by wire system, IEEE AMC2004, pp.31-34, Kawasaki, 2004

Liu, H.; Dong S. (2005). Uniform synchronization in multi-axis motion control , Proceedings of the American Control Conference, pp.4537-4542, 2005

Yan, M.; Lee, M. \& Yen, P. (2005). Theory and application of a combined self-tuning adaptive control and cross-coupling control in a retrofit milling machine, Mechatronics, Vol.15, No.2, pp. 193-211 


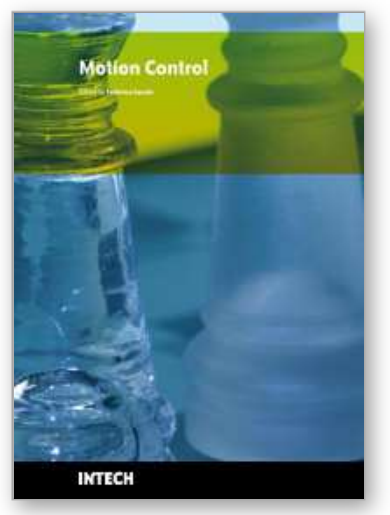

\author{
Motion Control \\ Edited by Federico Casolo
}

ISBN 978-953-7619-55-8

Hard cover, 590 pages

Publisher InTech

Published online 01, January, 2010

Published in print edition January, 2010

The book reveals many different aspects of motion control and a wide multiplicity of approaches to the problem as well. Despite the number of examples, however, this volume is not meant to be exhaustive: it intends to offer some original insights for all researchers who will hopefully make their experience available for a forthcoming publication on the subject.

\title{
How to reference
}

In order to correctly reference this scholarly work, feel free to copy and paste the following:

Yunhua Li and Liman Yang (2010). Motion Synthesis and Coordinated Control in the Multi-Axle-DrivingVehicle, Motion Control, Federico Casolo (Ed.), ISBN: 978-953-7619-55-8, InTech, Available from: http://www.intechopen.com/books/motion-control/motion-synthesis-and-coordinated-control-in-the-multi-axledriving-vehicle

\section{INTECH}

open science | open minds

\section{InTech Europe}

University Campus STeP Ri

Slavka Krautzeka 83/A

51000 Rijeka, Croatia

Phone: +385 (51) 770447

Fax: +385 (51) 686166

www.intechopen.com

\section{InTech China}

Unit 405, Office Block, Hotel Equatorial Shanghai

No.65, Yan An Road (West), Shanghai, 200040, China

中国上海市延安西路65号上海国际贵都大饭店办公楼 405 单元

Phone: +86-21-62489820

Fax: +86-21-62489821 
(C) 2010 The Author(s). Licensee IntechOpen. This chapter is distributed under the terms of the Creative Commons Attribution-NonCommercialShareAlike-3.0 License, which permits use, distribution and reproduction for non-commercial purposes, provided the original is properly cited and derivative works building on this content are distributed under the same license. 